\title{
Management of Relative Effective Transmission Rate in Packet Switching Networks
}

\author{
Olexandr Skopa, Volodymyr Korchynsky
}

\begin{abstract}
The opportunity of increase of an overall performance of a telecommunication network is considered at the expense of increase of relative effective speed of transfer of each element of system. The expediency of use of a mode of detection of mistakes and their partial correction is investigated at the varied statistical parameters of the channel.

Keywords - Data transmission systems, Effective transmission rate, Decision feedback, Simultaneous correction, Errorcorrection.

One of the tasks, which face packet switching networks, is transmission rate increase. One of the indexes data transmission systems performance efficiency with a decision feedback (DTS with DF), is relative effective transmission rate R[1].

Perspective of the rate increase $\mathrm{R}$ is possible at the expense of an automatic choice by a DT system with DF of an optimum behaviour of a correcting code in view of a current condition of the channel. With the purpose of study and the probing a possibility of control of relative effective rate in packet switching networks is considered excessive binary $(\mathrm{n}, \mathrm{k})$ code with code distance $d o=2 t_{i}+1$, where $t_{i}$ - multiplicity of an errorcorrection. In a mode of detection and errorcorrection such code can bi guaranteed to correct all errors of multiplicity not higher $t_{\text {iд }}$ and to determine all errors of multiplicity not higher $\mathrm{t}_{\mathrm{o} \sigma}$, if the condition is observed

$$
\mathrm{t}_{\text {ід }}+\mathrm{t}_{\text {об }}+1 \leq \mathrm{d}_{\mathrm{o}}
$$

where $t_{\text {іл }}$ - number of errors, which are corrected by the decoding device, $\mathrm{t}_{\mathrm{o} \sigma}$ - quantity of errors, which detect by a code. It is clear, in such mode of operation of a system that artificial potential possibilities of a code on detection of maximum multiplicity of an error on value tiд are underestimated.

The DT system with DF, incessant transmission and accumulation of group of symbol (DFas) is considered, that uses linear $(n, k)$ a code in a mode of a partial error correction of multiplicity not higher $\mathrm{t}_{\mathrm{iд}}$ and detection of errors of multiplicity not higher $2 \mathrm{t}_{\mathrm{i}}-\mathrm{t}_{\text {ід }}$.

In DT systems with DFas the relative effective transmission rate $\mathrm{R}$ can vary and appears as a function of a condition of the channel and parameters of transmission [2]

$$
\mathrm{R}=\gamma_{\mathrm{K}} \cdot \gamma_{\ni}=\frac{\mathrm{k}}{\mathrm{n}} \cdot \frac{1}{1+\frac{\mathrm{M} \cdot \mathrm{P}_{\mathrm{CT}}(\mathrm{n})}{1-\mathrm{P}_{\mathrm{CT}}(\mathrm{n})}},
$$

where $\gamma_{K}$ - relative factor of the rate of a code; $\gamma_{\ni}$ - relative factor of code efficiency of use of the channel stipulated by probability of erroneous reception of a unity element; $\mathrm{k}$ number of information elements in a code word n, M - quantity of iterated code words.

The value of parameters $\mathrm{R}, \gamma_{\mathrm{K}}$ and $\gamma_{\ni}$ is restricted by a range of numbers from 0 up to 1 . Thus the ratio $\mathrm{R}=\mathrm{k} / \mathrm{n}$ defines theoretical margin of a system effectiveness DT with a feedback. There is a possibility to approximate to theoretical mar- gin provided that the factors $\gamma_{K}$ and $\gamma_{\ni}$ raise up to 1 . So, at a choice of parameters and algorithm of transmission of a DT system with DFas it is necessary to take into account this condition[2].

The expression for account of relative effective transmission rate for a DT system with DFas in a mode of a correcting code is obtained which corrects and determines errors.

It is stated, that a DT system with DF and detection of errors of deterioration of quality of the channel, serves as a reason of occurrence of additional number of the distorted code patterns. Thus the part of the distorted code patterns with small multiplicity of errors is magnified and at the same time the number of the distorted code patterns with high multiplicity of errors diminishes. The last factor contributes to the expedient junction of a system to a mode of simultaneous correction and detection of errors, at which the deterioration of detecting abilities of a code is compensated by a condition of the channel with small probability of a defeat of a code pattern by the large multiplicity of errors. The reparation of errors of small multiplicity permits to lower quantity decision's feedbackes and, thereby, to increase R.

\section{CONCLUSION}

1. The formula for account of effective relative transmission rate for a DT system with DFas in a procedure of a partial errorcorrection of small multiplicity tід $<\mathrm{t} i$ with simultaneous detection of errors of restricted multiplicity not higher $2 \mathrm{t}$ $\mathrm{i}$-tiд is obtained.

2. The procedure of a partial errorcorrection is expedient for connecting to a procedure of detection of errors. The choice of a procedure is carried out a DT system with DF in view of current quality of the channel.

3. The procedure of detection of errors is recommended for a condition of the channel with large factor of bunching of errors $(a=1,8 \ldots 4,5)$, as in this case code can supply detection of errors of high multiplicity.

4. The procedure of an errorcorrection of small multiplicity and detection of errors of multiplicity not higher $2 \mathrm{t}$ i-tiд is recommended for a condition of the channel with low factor of bunching of errors $(\mathrm{a}<0,18)$, that is expedient for codes with small detecting properties.

\section{REFERENCES}

[1] Захарченко В.Н., Корчинский В.В., Гринь А.А. Эффективность систем ПД с РОС и переменными параметрами корректирующего кода / Радиотехника. 2000. Вып. 110.

[2] Захарченко Н.В., Корчинский В.В. Модель потока ошибок при исследовании систем передачи данных с переменными параметрами. / Сборник трудов УГАС им. А.С. Попова №1, 1999.

Olexandr Skopa, Volodymyr Korchynsky - department of document communication, Odessa National Acadamy names after A.S.Popov,

1, Chelyuskintsev Str., Odessa, 65029,UKRAINE,

E-mail: 40a@usa.net 